\title{
Non-Native Species and the Aesthetics of Nature
}

\author{
Christoph Kueffer ${ }^{1}$ and Christian A. Kull ${ }^{2}$
}

This is the author archived pre-print version of a paper published as Chapter 20 in the book Impact of Biological Invasions on Ecosystem Services, published by Springer as volume 12 of their series "Invading Nature - Springer Series in Invasion Ecology". The definitive final version is available via www.springer.com. To cite the chapter:

Kueffer, Christoph \& Christian A. Kull (2017) Non-native species and the aesthetics of nature. pp. 311-324 in Impact of Biological Invasions on Ecosystem Services, edited by Montserrat Vilà \& Philip E. Hulme. Berlin: Springer. DOI $10.1007 / 978-3-319-45121-3 \quad 20$

\begin{abstract}
${ }^{1}$ Institute of Integrative Biology, ETH Zurich, Universitätsstrasse 16, 8092 Zurich, Switzerland, \& Centre for Invasion Biology, Department of Botany and Zoology, Stellenbosch University, Matieland 7602, South Africa

${ }^{2}$ Institute of Geography and Sustainability, University of Lausanne, Mouline-Géopolis, 1015 Lausanne, Switzerland

e-mail: kueffer@env.ethz.ch, christian.kull@unil.ch
\end{abstract}

\begin{abstract}
How humans perceive and judge nature and relate it to their life is shaped by emotional, cognitive, cultural and social factors. Whether a species is considered native, non-native or invasive can affect such aesthetics of nature by interacting with our emotions, affronting or confirming our cognitive categories, or engaging in our social, economic and cultural worlds. Consequently, how humans perceive and judge the presence of such species, or how they judge an ecosystem or landscape change triggered by them, is not fixed and easy to define. Here, some of the psychological, cognitive, and social dimensions that influence how humans judge non-native and invasive species and their effects on ecosystems are reviewed. It is concluded, at least in the case of non-native species, that the reduction of aesthetics to a 'service' is problematic, for it occludes the complex psychological and social processes that shape divergent perceptions of changing species distributions.
\end{abstract}

Keywords aesthetics, cultural ecosystem services, history, judgement, landscape, nativism, perception, political ecology, psychology, social, valuation

\subsection{Introduction}

The ecosystem services literature considers the aesthetics of nature to be a key cultural ecosystem service (Daniel et al. 2012). Non-native species can affect the aesthetics of nature by interacting with our emotions, affronting or confirming our cognitive categories and worldviews, or engaging in our social, economic and cultural worlds (McNeely 2001; Hall 2003). They can contribute to, detract from, or simply alter the aesthetics of a particular nature.

How humans perceive and judge nature and relate it to their lives is shaped by emotional, cognitive, cultural and social factors (Gobster et al. 2007; Daniel et al. 2012). This applies whether 
the 'nature' we are talking about is an individual plant or animal, a patch (a backyard, a trailside forest, or piece of species-rich lowland tropical forest), or a landscape (seen and appreciated from a viewpoint). In short, there is no such thing as a universal aesthetics of nature. How we see and relate to nature in its manifold forms lies in the eye of the beholder. Consequently, how humans perceive and judge the presence of species that are considered non-native or invasive, or how they judge an ecosystem or landscape change triggered by such species, is not fixed and easy to define. Here, the psychological, cognitive, and social dimensions that influence how humans judge such species and their effects on ecosystems are reviewed (Table 20.1). The terms perception (or to perceive) and judgement (or to judge) are used for the process of describing human evaluation of nature. Perception is used as a psychological term that refers to the ways in which humans filter, organise and interpret information from the outside world; judgement more explicitly refers to the interpretive component - that is, how people assign values like 'good' or 'bad' to aspects of nature.

Human perception and judgement are complex processes. We distinguish between psychological, cognitive and social factors that can influence human perceptions of non-native and invasive species and their effects on ecosystems even though these three types of influences are necessarily intertwined (adapted from Kueffer 2013).

\subsection{Psychological Factors}

Our feelings towards a non-native species and its effects on the landscape can be shaped by the characteristics and 'reputation' of the species; by our reactions to landscape complexity or monotony; and by our perceptions of something being lost, such as a feeling of being at home in a place, or by our reaction to the rapid emergence of something new.

\subsubsection{Charismatic Species, and Species with a Negative Image}

There are species that have a positive image and others that have a negative one, and these judgements of particular species can be rooted in human psychology, but also shaped through the lens of culture. Deliberately introduced non-native species are often brought to a new place because of some desirable aesthetic characteristics, for instance 'cute' or 'charismatic' animals such as cats or rabbits (both considered problematic invasive species in some places) or plants with large and colourful flowers, such as the water hyacinth, Eichhornia crassipes. These positive characteristics can make it hard to explain to people why a problematic species should be removed (Fig. 20.1). Equally, some species have a bad image, which can add to or trigger negative perceptions of the species even when it might have no strong measurable negative ecological effects: it is easier to gain support for a black rat, Rattus rattus, eradication programme than efforts that target grey squirrels, Sciurus carolinensis, which, for instance, triggered opposition by animal welfare groups in Italy. In turn, it also matters whether the biota threatened by an invasion is charismatic or not. A control programme against non-native predators of endemic birds might get support, while the necessity to manage an invasion of earthworms affecting soil biota might be more difficult to communicate to a general public.

\subsubsection{Monotony, Overabundance, and Loss of Diversity}

Invasive species are represented by a wide range of taxonomic groups, forms, colours and effects on landscapes and ecosystems. Thus, there is no generalisable effect on the visual appearance of an 
ecosystem or a landscape. There is, however, one general feature that is often considered to be associated with biological invasions (Humair et al. 2014b): this is the fact that they tend to lead to less diverse and more monotonous communities, ecosystems and landscapes that are characterised by the abundance of a single or few species (Fig. 20.2).

How people perceive such landscape characteristics, and more specifically heterogeneity or monotony, is highly dependent on cultural contexts and expectations for a particular type of landscape, whether it is a wilderness area, rural agricultural landscape, or an urban place (e.g., Gobster et al. 2007). Historical cultural landscapes shaped by extensive land-use for instance are often appreciated for their heterogeneous mosaic (e.g., van Zanten et al. 2014), while monotony that triggers feelings of vastness or solitude might be appreciated in an Arctic wilderness area. Whether humans have an innate preference for certain types of landscapes, for instance, for those of intermediate heterogeneity and diversity is an open research question (Ode et al. 2010). There is certainly not a general and undisputed dislike of monotonous landscapes, for instance, a spectacular bloom of one plant species, such as gorse, Ulex europaeus, over an entire landscape can trigger feelings of natural wonder (Fig. 20.2).

Sense of place There is no doubt that local nature can play an important role in helping people feel at home in a place. But the link between sense of place and the presence of non-native species is often not obvious (e.g., Humair et al. 2014b). One reason is that humans tend to adapt quickly to a new situation and often forget the nature of the past within a human generation or less ('shifting baseline syndrome'). For instance, in Madagascar, farmers considered non-native plants like lantana, Lantana camara; Moluccan bramble, Rubus alceifolius; silver wattle, Acacia dealbata; and paperbark, Melaleuca quinquenervia; as normal, indeed 'native', parts of the Malagasy landscape despite the fact that all were introduced. Very recent arrivals, however, were quickly noticed and evaluated for their utility or threat (Kull et al. 2011).

People will often consider the species that they grew up with as particularly important, whether they are unique native species, native species that profited from anthropogenic land use, planted or naturalised non-native species (Humair et al. 2014b). Marris (2011) argued that when people grow up in novel ecosystems often dominated by non-native species, for instance in urban or suburban areas, then such novel nature is the nature that matters to them; and it is such nature that they engage with emotionally and through their actions. This also highlights that for understanding perceptions of change it is important to know what states people use for comparison. For instance, in the American Midwest, a flowering meadow of knapweeds, Centaurea sp., might be valued negatively if compared to a field of native sagebrush, particularly if the knapweed caused this change, but viewed positively if compared to an overgrazed and disturbed pasture, which may have enabled the knapweed invasion in the first place.

Another factor complicating the link between non-native species and sense of place is that we live increasingly in a time of rapid social change, widespread movement of people, and multicultural societies. Many people did not grow up in the places where they live today, and therefore today's local biota is not the same they encountered in their childhood. In fact, it is often plants and animals from their previous homes, often non-native species that help people to feel at home in a new and foreign place. This is one reason why people introduce non-native plants to new places (e.g., Daehler 2008). 
Rapid change and novelty Invasive species can cause rapid ecological change. How people perceive such changes in their surroundings and their encounters with something novel has been studied by psychologists, including those working on risk. Novelty tends to be seen as risky and negative, while with exposure, people's risk perception and negative feelings tend to decrease (cf. Humair et al. 2014a). These reactions appear to be rooted in human psychology, relatively independent of culture. One mechanism that psychologists have identified is called 'mere exposure effect' (cf. Humair et al. 2014a). Humair et al. (2014a) showed that it was the novelty of a species, more than its non-nativeness that led to increased perceptions of risk by horticultural practitioners in Switzerland. This effect decreased with the duration and intensity of interaction between a horticulturalist and a novel species. The opposite also held: horticulturalists tended to view nonnative species that were important to their business as less problematic because they knew them well.

People differ in how they react to novelty. To use again the example of horticultural plants, novel plants might be valued highly because they are new, exciting or something that others don't have, but people might also prefer plants that they have known for a long time because it generates a feeling of continuity, and assures them that they know how to grow it and how their friends will react to them. There are wide variations among people's perception of change and novelty. While some prefer a cautious approach to ecosystem change, others favour experimentation in nature and will more positively value new species and landscapes (Gross 2010). This also implies that people think differently about approaches towards non-native and spreading species.

\subsection{Cognitive Factors: Knowledge and Reasoning}

Knowing and reasoning about the ecology and cultural significance of particular non-native species, their effects on ecosystem services, and available management options is important for shaping perceptions (reviewed in Kueffer 2013). A person who knows about specific negative impacts of a non-native species on native biodiversity, will associate negative feelings with this species, even if it is beautiful. It has been shown that the role of knowledge is stronger when this comes from personal experiences with problematic aspects of an invasive species, but also more general knowledge ('competence') about non-native species, nature, and nature conservation can influence perception of non-native species.

However, it is important to recognise that knowledge is relative: it can be strongly influenced by worldviews, values, and the workings of institutional power. Knowledge is often transported through value- and power-laden concepts, categories, and metaphors (Kull and Rangan 2015; Kueffer and Larson 2014). Below, we discuss some of these notions.

\subsubsection{Invasive Species and Biological Invasions}

How the spread and presence of novel species, and the change induced by them, is represented in language, metaphor, stories and visualisation affects how people perceive them and the resulting landscapes. In this context, the use of notions such as 'invasive' or 'invasion' has been amply discussed (Kull and Rangan 2015; Kueffer and Larson 2014; Larson 2005). Labelling a new species spreading in the landscapes as 'invasive' gives rise to different perceptions than saying that the species is 'extending its distribution'. The rhetorical framework of 'invasion' can for instance wrongly give the impression of rapid change, when a biotic change might actually have happened 
over long time periods, and on the other hand can move attention away from more incremental, but equally fundamental changes.

\subsubsection{Native and Non-Native}

Another key concept is the nativeness or non-nativeness of a species. Beyond being a concept used by scientists, this is also a notion that has a long and diverse cultural history, often tied to ideas of nationalism (Hall 2003, Kull and Ragan 2015). The concept of a non-native or native species can differ substantially between different experts, the public and experts, and among different social groups or individuals (Humair et al. 2014b). The cultural history of the notion influences how humans perceive non-native species and these influences can differ depending on which term is used, e.g. alien, adventive, exotic, foreign, introduced, neobiota, non-indigenous, or non-native. Even if scientists attempt to use the term 'native' only with a specific and 'scientific' meaning, they cannot neglect that the connotations of the term in a particular cultural context will influence how people think about 'non-native' species, and perceive and value them in the landscape.

\subsubsection{Wilderness, Concepts of Naturalness and Ecological Order, and the Perceived Role of Humans in Nature}

How people perceive a landscape, and species in this landscape, depends on the expectations people have for this landscape (e.g., Gobster et al. 2007). When it comes to valuing 'natural' landscapes it matters how people think of nature, what their concepts of naturalness are, and how they perceive the role of humans in nature (e.g., Fischer and van der Wal 2007; Carlson and Lintott 2008). For instance, people may differ in their understanding of how nature is organised, whether it is in a stable balance or in constant flux, or whether it is well-ordered or chaotic. Novel species and associated changes will be perceived more positively by those people that see nature as something constantly changing than by others who hold on to the ideal of balance of nature (e.g., Fischer and van der Wal 2007). The idea that integrity, stability, and balance are defining characteristics of 'pristine' nature (i.e. nature not influenced by humans) have been very influential in the Western context. Aldo Leopold, one of the pioneers of $20^{\text {th }}$ century nature conservation in the US, for instance attempted to develop an aesthetics of nature's beauty that built on the perceived special qualities of ecosystems shaped by long-term co-evolution and ecological ordering. Leopold's aesthetic is more about a sophisticated, cognitive appreciation of these qualities than about visual beauty (Callicot 1983). Leopold also referred to introduced species as a threat to such order and thereby exemplifies a view that sees introduced species as disturbing the integrity of ecosystems and thereby their beauty (reviewed in Simberloff 2012).

The concepts of wilderness and wild nature are also particularly important. Wilderness, in its current dominant usage in the context of biological conservation, generally refers to areas where humans (and their influences) are absent. But it is important to acknowledge that concepts of wilderness often vary between sociocultural contexts, change with time, and are very much a human-created idea (Cronon 1996). Today, the wilderness is often seen as an idyllic place, contrasting a noisy and stressful daily life in a modern civilisation, and associated with positive but strongly contrasting ideas, such as vastness, frontier, adventure, solitude, or exotic places. In contrast, in the past, the wilderness was often associated with negative feelings, such as danger of wild animals, bandits, or lack of shelter from dangerous weather events. Correspondingly 'wild' still today stands for dangerous, unplanned, unmanaged, unpredictable or chaotic. The 'wilderness' 
concept is important in the context of non-native species, because non-native species are often considered to be species that are brought to a new place through human agency and therefore turn wild places into nature touched by humans. However, the self-propagated expansion of a novel species into a natural area can add 'wildness' in the sense of unpredictable and unplanned processes, while the planned control or eradication of a non-native species in a wilderness area brings an element of design to an area not meant to be shaped by humans. The wilderness concept thus touches upon underlying paradoxes that guide peoples' perceptions of non-native species.

\subsection{Social, Economic and Historical Factors}

It is crucial to understand human perceptions of non-native species, their effects, and their management in their particular social and economic contexts, shaped by the particularities of geography and history at multiple scales (Kull et al. 2011). Peoples' perceptions are shaped by economic interests, cultural traditions, symbolic representations, social relationships, and other factors that are difficult to understand outside the local, regional, or national context.

An obvious factor is the utility or nuisance of a non-native species in particular landscapes. People who profit from the presence of a species will perceive it differently from those whose economic activities are negatively affected. A classic example is Echium plantagineum, a European herb introduced to Australia that was nicknamed "Salvation Jane" by dryland grazers and apiculturalists who appreciated it, and "Patterson's curse" by farmers who despised it (Cullen and Delfosse 1985).

Values related to non-native species are also rooted in the history or culture of a society. Some non-native species play, or played in the past, an important role in the culture of a society; for instance the candlenut tree, Aleurites moluccana, introduced by Polynesians to Pacific islands. The appreciation of silver wattle, Acacia dealbata, in France reflects its now long-term association with the landscapes of the Côte d'Azur despite evidence of invasion.

Ideas linked to nationalism can also influence the perceptions of 'native' and 'non-native' species. In $19^{\text {th }}$ and early $20^{\text {th }}$ century Germany, the promotion of native plants in landscaping was strongly associated with nation building. In settler colonies, like Australia and South Africa, the identification with 'indigenous' flora and fauna from the new place, as well as familiar land use systems with their associated biotas transported from Europe, served in building a new national identity. In such cases, nationalistic ideas can accentuate negative or positive perceptions of either native or non-native species.

Any human judgement is influenced by broader concepts that are culturally-rooted and value-laden, but this entanglement of personal affection and culture might be particularly tight and dynamic in the case of biological invasions. This is because the terms non-native and invasive have strong connotations and a rich history, and biological invasions also interfere with some of the most fundamental ideas about human relationships with nature, such as wilderness, cultural heritage, 'pristine' nature, or balance of nature. In modern societies, science has a strong influence on the production and reception of such notions and consequently changing evaluations of non-native species are often the result of a tight entanglement of changing expert paradigms and evolving social and cultural views (that can be the result of shifts in power relationships) (e.g., Stromberg et al. 2009). Salt-cedar Tamarix sp., for instance, was introduced to USA in the late 1800s and early 1900 s to rehabilitate degraded land. Only a few decades later, by the mid-1900s, the species was combated because it was considered a problematic species negatively affecting water resources. Recently, some experts have portrayed the species once again more positively (Stromberg et al. 
2009). Similarly, views of German foresters towards black cherry, Prunus serotina, varied over time and with forestry practices and scientific advice. Their perceptions were initially based on their hopes for timber or soil improvement, later on their fears about invasion, and then on their hopes for mitigation and living with the species (Starfinger et al. 2003). These discourses were only partly based on fact.

Social factors and social relationships have recurrently been shown to affect the perception and judgement of non-native and invasive species (reviewed in Kueffer 2013). The socioeconomic or demographic background of a person matters, and so too does the social or interest group to which a person belongs. For instance, tourists, nature conservation managers, or local residents can differ in their perception. In Australia, rivalry between community groups that competed for funding and media attention to combat cane toads, Rhinella marina, affected support of control measures against the species (Shine and Doody 2011). In summary, the perception of the aesthetics of landscapes and their biotas can often not be separated from the social relationships of those that live in the landscape or from the history of human-nature relationships in a place.

\subsection{Aesthetics of Nature - An Ecosystem Service?}

Aesthetics and other categories of 'cultural ecosystem services' have always been difficult to integrate into ecosystem services conceptualisations due to their subjectivity, intangibility, and nonquantifiability (Daniel et al. 2012). Non-native species clearly have effects on aesthetics' subjective and relative characteristics. An underlying assumption of applying the ecosystem services concept to biological invasions is that the provision of these services changes through the effects of nonnative species on the biology and ecology of the place. Yet the cultural service of aesthetics cannot simply be said to 'exist' in physical space when its character is so much in the eye of the beholder and his or her cultural and social context. Certainly the presence of 'nature' gives people something to behold, but the appreciation and judgement of aesthetics is a complex human psychological and social endeavour that is partly independent of biophysical changes to this nature.

Such interpretative fluidity is a challenge for the ecosystem services conceptual system as well as for environmental management. Yet the difficulty of fitting aesthetics into the rubric of cultural ecosystem services, and the lack of immediate management consensus on non-natives from an aesthetic aspect also has a flip side: the fact that perceptions of aesthetics are relative and socially-influenced. This opens up space for shaping such perceptions through advocacy. Notions such as 'non-native' and 'invasive' have in the past been used strategically to bring actors together behind a common cause. Yet such rhetorical strategies have been criticised because they build on problematic, violent and exclusive discourses (Larson 2005). There is little doubt that conservationists should highlight the values of past and current nature and warn of the risks posed by some non-native species to the ecological functioning and the uniqueness of ecosystems. Such advocacy will however only be effective if it engages with the psychological, social and cultural relationships that people have with their surrounding nature. The normative views that are implicit in conservationists' ways of representing 'biological invasions' must be made explicit, thereby opening them to transparent deliberation (e.g., Kueffer and Larson 2014; Kueffer and Hirsch Hadorn 2008; Gobster et al. 2007).

\subsection{Conclusions}


There are psychological, cognitive, and social dimensions that influence how humans judge nonnative and invasive species and their effects on ecosystems. It is concluded, at least in the case of non-native species, that the reduction of aesthetics to a 'service' is problematic, when its character is so much in the eye of the beholder and his or her cultural and social context. The cultural service of aesthetics cannot simply be said to 'exist' in physical space. Rather, how humans relate to nonnative species is part of an entangled and dynamic web of psychological factors, interests, social relationships and cultural views of plants and animals, of landscapes, of nature as a whole, and of the place of humans in it.

\section{Acknowledgements}

This work was partly supported by the National Socio-Environmental Synthesis Center (SESYNC; NSF DBI-1052875), the Helmholtz Centre for Environmental Research - UFZ, and sDiv, the Synthesis Centre of iDiv (DFG FZT 118).

\section{References}

Carter J, Leonard BP (2002) A review of the literature on the worldwide distribution, spread of, and efforts to eradicate the coypu (Myocastor coypus). Wildlife Soc B 162-175

Copp GH, Bianco P, Bogutskaya N et al (2005) To be, or not to be, a non-native freshwater fish? J Appl Ichthyol 21(4):242-262

Cronon W (1996) Uncommon ground: Rethinking the human place in nature. In: Norton W (ed) Uncommon ground: Rethinking the human place in nature. William Cronon, editor. New York, p 69-90.

Cullen JM, Delfosse ES (1985) Echium plantagineum: catalyst for conflict and change in Australia. In: Delfosse ES (ed) Proceedings of the VI International Symposium on Biological Control of Weeds, 19-25 August 1984. Agr Can, Vancouver, Canada, p 249-292

Daehler CC (2008) Invasive plant problems in the Hawaiian Islands and beyond: insights from history and psychology. In: Tokarska-Guzik B, Brock JH, Brundu G et al (eds) Plant Invasions: Human perception, ecological impacts and management. Backhuys Publishers, Leiden, The Netherlands, p 3-20

Daniel TC, Muhar A, Arnberger A et al (2012) Contributions of cultural services to the ecosystem services agenda. Proc Nat Acad Sci U S A 109(23):8812-8819

Fischer A, van der Wal R (2007) Invasive plant suppresses charismatic seabird - the construction of attitudes towards biodiversity management options. Biol Conserv 135(2):256-267

Gobster PH, Nassauer JI, Daniel TC et al (2007) The shared landscape: what does aesthetics have to do with ecology? Landscape Ecol 22(7):959-972

Gross M (2010) Ignorance and surprise: science, society, and ecological design. MIT Press, Cambridge, Massachusetts

Hall Me (2003) The native, naturalized and exotic - plants and animals in human history. Landscape Res 28(1):5-137

Humair F, C K, Siegrist M (2014a) Are non-native plants perceived to be more risky? Factors influencing horticulturists' risk perceptions of ornamental plant species. PLoS One 9(7):e102121. doi:102110.101371/journal.pone.0102121. 
Humair F, Siegrist M, Edwards PJ et al (2014b) Understanding misunderstandings in invasion science: why experts don't agree on common concepts and risk assessments. Neobiota 20:130

Kueffer C (2013) Integrating natural and social sciences for understanding and managing plant invasions. In: Larrue S (ed) Biodiversity and society in the Pacific Islands. Presses Universitaires de Provence. Collection "Confluent des Sciences" \& ANU ePress, Marseille, France \& Canberra, Australia, p 71-96

Kueffer C, Hirsch Hadorn G (2008) How to achieve effectiveness in problem-oriented landscape research: the example of research on biotic invasions. Living Reviews in Landscape Research 2:2 http://www.livingreviews.org/lrlr-2008-2002

Kueffer C, Larson BM (2014) Responsible use of language in scientific writing and science communication. BiosSience 64:719-724

Kull CA, Rangan H (2015) The political ecology of weeds: a scalar approach to landscape transformation. In: Bryant R (ed) The international handbook of political ecology. Edward Elgar, Cheltenham, p 487-500

Kull CA, Shackleton CM, Cunningham PJ et al (2011) Adoption, use and perception of Australian acacias around the world. Divers Distrib 17:822-836

Larson B (2005) The war of the roses: demilitarizing invasion biology. Front Ecol Environ 3(9):495-500

Marris E (2011) Rambunctious garden. Saving nature in a post-wild world. Bloomsbury New York, NY

McNeely JA (2001) The great reshuffling. Human dimensions of invasive alien species. IUCN, Gland, Switzerland

Shine R, Doody JS (2011) Invasive species control: understanding conflicts between researchers and the general community. Front Ecol Environ 9(7):400-406

Simberloff D (2012) Integrity, stability, and beauty: Aldo Leopold's evolving view of nonnative species. Environ History 17(3):487-511

Stromberg JC, Chew MK, Nagler PL et al (2009) Changing perceptions of change: the role of scientists in Tamarix and river management. Restor Ecol 17(2):177-186

van Zanten BT, Verburg PH, Koetse MJ et al (2014) Preferences for European agrarian landscapes: A meta-analysis of case studies. Landscape Urban Plan 132:89-101 
Table 20.1 Paradigmatic examples of complex, ambivalent, controversial, or changing perceptions of non-native species and their effects on landscapes, ecosystems and society

\begin{tabular}{|c|c|c|}
\hline Species & Description & References \\
\hline Acacia spp. & $\begin{array}{l}\text { Australian acacias have been introduced to many regions around the world for diverse } \\
\text { purposes ranging from beautification to timber production. Uses and perceptions of acacias } \\
\text { in particular regions have often fundamentally shifted in time, and often they have become an } \\
\text { important part of cultural identity or livelihoods of some social groups while they are } \\
\text { combated as weeds or invasive species by others. }\end{array}$ & Kull et al. 2011 \\
\hline $\begin{array}{l}\text { Cinnamomum verum J. } \\
\text { Presl. }\end{array}$ & $\begin{array}{l}\text { Introduced to the Seychelles for spice production in the } 18^{\text {th }} \text { century, in the } 19^{\text {th }} \text { century it } \\
\text { colonized large parts of the deforested islands. Naturalized cinnamon restored forest cover } \\
\text { and reduced erosion, and it supported for several decades a cinnamon industry that formed } \\
\text { the backbone of the national economy. With the rise of nature conservation in the late } 20^{\text {th }} \\
\text { century, it was considered the most problematic invasive plant species, while at present it is } \\
\text { more often acknowledged as an integral part of novel ecosystems and local history with value } \\
\text { for ecotourism. }\end{array}$ & $\begin{array}{l}\text { Kueffer et al. } 2013 \\
\text { e }\end{array}$ \\
\hline $\begin{array}{l}\text { Echium plantagineum } \\
\text { L. }\end{array}$ & $\begin{array}{l}\text { A European herb introduced to Australia that was nicknamed "Salvation Jane" by dryland } \\
\text { grazers and apiculturalists who appreciated it and "Patterson's curse" by farmers who } \\
\text { despised it. }\end{array}$ & Cullen and Delfosse 1985 \\
\hline Tamarix sp. & $\begin{array}{l}\text { Salt-cedar was introduced to USA in the late } 1800 \text { s and early } 1900 \text { s to rehabilitate degraded } \\
\text { land. Only a few decades later by the mid-1900s the species was combated because it was } \\
\text { considered a problematic species negatively affecting water resources. Recently, some } \\
\text { experts have portrayed the species once again more positively. }\end{array}$ & Stromberg et al. 2009 \\
\hline Fish species & $\begin{array}{l}\text { A long history of introducing fish to aquatic systems around the world led to a complex } \\
\text { concept of what constitutes a non-native species integrating both biological and } \\
\text { socioeconomic aspects. }\end{array}$ & Copp et al. 2005 \\
\hline $\begin{array}{l}\text { Sciurus carolinensis } \\
\text { Gmelin }\end{array}$ & $\begin{array}{l}\text { When controlling animal species such as grey squirrels conservation of threatened native } \\
\text { species can be in conflict with values of animal rights and welfare. In Italy, animal rights } \\
\text { groups used legal means to prevent an eradication attempt of grey squirrels. }\end{array}$ & McNeely 2001 \\
\hline $\begin{array}{l}\text { Myocastor coypus } \\
\text { Molina }\end{array}$ & $\begin{array}{l}\text { Introduced worldwide for fur production, in several places leading to local keystone } \\
\text { industries, it is now often considered an invasive species. In some places it was at times } \\
\text { protected by law due to overharvest. In Germany perception differed substantially between } \\
\text { Western and former Eastern Germany. While it was considered a conservation problem in the } \\
\text { West, it was of socioeconomic importance including as a source of meat in the East. There } \\
\text { are organised supporters of the species in Germany and material on, e.g., Youtube shows } \\
\text { how it is perceived as an element of 'wild' and special nature in some cities. According to } \\
\text { IUCN's red list it is considered threatened in some parts of its native range. }\end{array}$ & Carter and Leonard $2002^{\mathrm{a}}$ \\
\hline
\end{tabular}

ahttp://www.nutria-info.com/gute-argumente-für-die-nutrias/ 


\section{Figure Legends}

Fig. 20.1 Coypu, Myocastor coypus, is widely considered an invasive species, but it is also appreciated as an attractive addition to the fauna and nature experience in cities such as Halle, Germany. Photograph: Sylvia Haider

Fig. 20.2 A landscape invaded by gorse, Ulex europaeus, on the Big Island of the Hawaiian archipelago (Pacific Ocean). Photograph: Eva Schumacher

Fig 20.3 Pillar Rocks, a tourist attraction in the Palni Hills of southern India. Non-native black wattles, Acacia mearnsii, planted on montane grasslands for tanbark, now contribute to visitor satisfaction but pose challenges due to invasiveness. Photograph Christian Kull 